\title{
A teoria queer e os intersex: experiências invisíveis de corpos des-feitos"
}

\author{
Nádia Perez Pino**
}

\section{Resumo}

A teoria queer emergiu como uma corrente teórica que colocou em xeque as formas correntes de compreensão das identidades sociais no mesmo período em que a problemática dos intersex se tornou socialmente visível. Apesar disso, a reflexão queer sobre os intersex é muito recente. Os intersex impõem reflexões sobre experiências invisíveis, paradoxos identitários e os limites do que compreendemos como humano. Neste artigo, exploro as diferentes definições sobre quem são os intersex, como a teoria queer lida com eles e, concluo com uma reflexão sobre a experiência corporal dos sujeitos marcados como intersex.

Palavras-chave: Intersex, Paradoxos Identitários, Invisibilidade, Sexualidade, Teoria Queer.

\footnotetext{
* Recebido para publicação em fevereiro de 2007, aceito em abril de 2007.

*** Mestranda em Ciências Sociais, Universidade Federal de São Carlos/UFSCar. nadiabud@yahoo.com.br
} 
A teoria queer e os intersex

Queer Theory and the Intersex:

Invisible Experiences of Un-Done Bodies

\begin{abstract}
Queer theory emerged as a theoretical orientation that challenged current forms of understanding social identities at the same moment when the question of the intersex became socially visible. In spite of this, queer reflection on the intersex is fairly recent. The intersex require reflection on invisible experiences, identity paradoxes and the limits of what we understand as human. In this article, I explore the different definitions of who are the intersex, how queer theory deals with them and I conclude with a reflection on the bodily experience of subjects marked as intersex.
\end{abstract}

Key Words: Intersex, Identity Paradoxes, Invisibility, Sexuality, Queer Theory. 
Nádia Perez Pino

\section{Experiências invisíveis}

Tornar visível a experiência de alguém invisibilizado socialmente, ou melhor, de uma identidade marcada como abjeta e/ou estigmatizada, seria suficiente para escrever sua história? Segundo a historiadora e teórica feminista Joan W. Scott (1998), o caminho que parte da identidade como auto-evidente e busca retraçar sua história constitui um procedimento teórico equivocado. Embora tenha sido considerado durante muito tempo um procedimento exitoso para aqueles empenhados em escrever as histórias das diferenças socialmente construídas, essa estratégia como "porto seguro" das explicações pode resvalar para o oposto: de uma tentativa construcionista pode recair no essencialismo que toma como dadas identidades sociais, o que terminaria por invisibilizar os processos que constituíram esses sujeitos.

Os estudos que partem das identidades e voltam-se para a reconstituição de suas histórias as encaram como fixas e, portanto, tomam como ponto de partida da investigação o que deveria ser o de chegada. Para Scott, a experiência não deve ser o ponto de partida da explicação, antes o que devemos explicar, isso porque são as experiências que constituem os sujeitos e não os sujeitos que têm experiências. Um novo procedimento teóricometodológico que problematize as identidades por meio de uma reconstituição e análise das experiências dos sujeitos em questão permite problematizar não as identidades, mas os processos sociais envolvidos em sua construção. ${ }^{1}$

Os intersex constituem mais uma daquelas identidades que associamos à invisibilidade, pois sobre eles pouco se sabe e pouco se fala. A maior prova do desconhecimento, do silêncio ou, nas palavras de Mariza Corrêa (2004), "do segredo" em torno da condição intersex, é que apenas recentemente o assunto deixou

${ }^{1}$ A autora também alerta para a necessidade de examinar "as pressuposições e as práticas que excluíram as considerações da diferença" exigindo assim uma revisão dos conceitos nos quais o conhecimento é formado, inclusive do próprio conceito de experiência (Scott, 1998:25). 
A teoria queer e os intersex

de ser restrito aos saberes médicos e biológicos sendo progressivamente incorporado pelas discussões sociológicas, antropológicas, pela crítica feminista e pelos estudos queer. A intersexualidade suscita importantes reflexões sobre os paradoxos identitários quase invisíveis, propiciando análises sobre a construção do corpo sexuado, seus significados sociais e políticos, assim como sobre o processo de normalização e controle social não apenas dos intersex, mas também de todos os corpos.

A experiência intersex mostra em níveis extremados a normalização compulsória dos corpos e das identidades, pois evidencia a restrição das identidades de gênero ao binarismo homem-mulher e a das identidades sexuais a uma suposta coerência necessária entre corpo sexuado, práticas e desejos. Tudo se inicia logo após o nascimento, quando a genitália de um bebê não responde claramente a questão: É menino ou menina? A dubiedade faz com que a medicina inicie uma série de intervenções corporais como as cirurgias de "correção genital" $e$ tratamentos hormonais. Por meio desses procedimentos médicos dispensados aos intersex, podemos perceber os significados sociais e culturais atribuídos ao corpo, assim como as relações políticas que constroem nossos corpos.

Em outras palavras, uma reflexão sobre a experiência intersex não deve se pautar apenas em discussões sobre estigma ou estranhamento causado por um corpo que não se enquadra nas representações culturais vigentes. Uma reflexão propriamente queer sobre os intersex pode problematizar as exigências sociais férreas, mesmo que não evidentes, sobre como devem ser homens e mulheres em nossa sociedade, como estas identidades binárias não são naturais, antes produto de ideais regulatórios que regem sua construção.

Quem são os intersex? Ao buscar a resposta, o que se encontra é um emaranhado de definições vindas de diferentes sujeitos e de diferentes discursos, como os ativismos intersex $e$ a perspectiva da medicina. Tentar resolver os impasses acerca da definição mais correta talvez não seja o melhor caminho, 
justamente porque é na indefinição do termo que podemos analisar os muitos significados atribuídos aos intersex.

Intersex é um termo de origem médica que foi incorporado pelos ativismos para designar as pessoas que nascem com corpos que não se encaixam naquilo que entendemos por corpos masculinos ou femininos. Segundo a ISNA ${ }^{2}$, intersex é uma definição geral usada para explicar a variedade de condições nas quais as pessoas nascem com órgãos reprodutivos $e$ anatomias sexuais que não se encaixam na típica definição de masculino ou feminino. ${ }^{3}$ São corpos que destoam de nossos parâmetros culturais binários, que embaralham e causam estranheza para aqueles que os vê ou que não se enquadram no que Susan Bordo chama de representações de corpos inteligíveis que "abrange nossas representações científicas, filosóficas e estéticas sobre o corpo - nossa concepção cultural de corpo, que inclui normas de beleza, modelos de saúde e assim por diante" (Bordo, 1997:33). São corpos que deslizam nas representações do que se considera como verdadeiramente humano, situando-se nos interstícios entre o que é normal e o que é patológico. Esta "não-humanidade" ou "anormalidade" justificará as intervenções médicas com o intuito de adequá-lo ao ideal do dimorfismo sexual.

É muito comum à associação do intersex com o hermafrodita, pessoa que possui os dois sexos. Segundo Mauro Cabral, ativista intersex e pesquisador da temática, essa associação presente em nosso imaginário cultural é oriunda das artes e da mitologia, mas não condiz com a realidade do corpo intersex, sendo que o conceito chave para entender a

2 Primeira organização política de ativismo intersex. A ISNA-Intersex Society America foi fundada em 1993 por pessoas que sofreram as cirurgias quando crianças. O objetivo geral dessa associação é "acabar com a vergonhosa, segregante e não desejada cirurgia genital", lutando para que as cirurgias sejam feitas apenas quando os pacientes puderem decidir por eles mesmos. Essa associação conta também com a presença de médicos e profissionais da área ciências humanas. (www.isna.org)

3 "Who is the intersex"? Retirado do site www.isna.com, em 12/06/2006. 
A teoria queer e os intersex

intersexualidade é a variedade, já que o corpo intersex não encerra um corpo único, mas um conjunto amplo de corporalidades possíveis (Cabral \& Benzur, 2005:284).

A variedade de formas e de corporalidades a que Cabral se refere é oriunda das diversas etiologias que originam a intersexualidade. ${ }^{4}$ A genitália ambígua ou indefinida é uma das ocorrências mais freqüentes. No entanto, há casos em que as pessoas nascem com órgãos genitais identificáveis com um sexo, mas estes não são representativos daquilo que é considerado ideal - clitóris grandes e pênis pequenos são chamados de "femininos masculinizados" ou "masculinos feminilizados". Há outros casos

4 Segundo Fausto-Sterlling (2005:52) os tipos mais comuns de intersexualidade são: Hiperplastia Congênita Adrenal: Causas: geneticamente herdada, o que implica o mau funcionamento de uma ou das seis enzimas envolvidas nos processos de produção dos hormônios esteróides. Características clínicas básicas: Em crianças podem causar a masculinização das genitálias ou alterações, que são visíveis no momento do nascimento, se não forem tratadas podem causar masculinização até a puberdade ou no início da puberdade. Síndrome da insensibilidade ao andrógino: Causas: Geneticamente herdada, o que modifica a superfície de recepção da célula em relação à testosterona. Características clínicas básicas: crianças XY nascem com genitálias muito feminilizadas. O corpo é "cego" em relação à presença da testosterona, as células não fazem uso da testosterona, o que ocasiona o desenvolvimento das características masculinas. Até a adolescência as crianças desenvolvem seios e formas corporais femininas. Disgenia Gonodal: Causas: Várias causas, nem todas genéticas. Características clínicas básicas: se refere a indivíduos (em geral, XY) cujas gônadas não se desenvolvem direito. As características clínicas básicas são heterogêneas. Hiposplastia: Causas: Várias causas, incluindo alterações no metabolismo da testosterona. Características clínicas básicas: A uretra não acaba na ponta do pênis. Em suas formas mais leves, a abertura é "tímida" na ponta do pênis, em suas formas mais moderadas, é alongada até a haste, e, em suas formas mais severas pode abrir a base do pênis. Síndrome de Turner: Causa: mulheres com falta do cromossomo X. Características clínicas básicas: é uma forma de disgenesia gonodal em mulheres. Os ovários não se desenvolvem; essas mulheres têm estatura baixa, carência de estrógeno e hormônios do crescimento. Síndrome de Klinefelter: Causa: Homens com cromossomo extra (XXY). Características clínicas básicas: é uma forma de disgenesia que causa a infertilidade. Depois da puberdade, freqüentemente, o peito e os ombros se alargam, o tratamento inclui terapia da testosterona. 
Nádia Perez Pino

de pessoas que nascem com todas as características hormonais, genéticas, do sexo, por exemplo, uma mulher com cromossomos $\mathrm{XX}$, com útero, ovários, mas sem vagina. Ou nos casos em que as pessoas nascem com mosaicos genéticos como XXY. Nem sempre a intersexualidade está ligada a uma condição de nascimento, mas se manifesta na adolescência, como no caso da síndrome de Klinefelter, na qual o problema não reside no diagnóstico de genitália ambígua, mas no desenvolvimento dos caracteres secundários de cada sexo. A intersexualidade, ainda, pode passar desapercebida até o momento em que a pessoa viva a situação na qual se exige a verificação dos órgãos reprodutivos internos como nos diagnósticos de infertilidade. ${ }^{5}$ Entretanto, é importante destacar que em poucos casos a intersexualidade causa danos à saúde. Conforme Cabral, a intersexualidade não é uma doença, mas uma condição de não conformidade física com os critérios culturalmente definidos de normalidade corporal (Cabral, 2003:121).

Apesar destes variados tipos de estados intersexuais, é importante observar que intersex é um termo socialmente construído que reflete uma real condição biológica, ou seja, os corpos realmente apresentam características que divergem dos corpos masculinos ou femininos. Os significados atribuídos a essa variação dependem não só das maneiras como o corpo intersex é visto pelas diferentes instâncias discursivas, mas também das concepções aceitas sobre o que deve ser o "corpo normal". Dessa forma, a divergência de significados - seja no sentido de patologizar ou de assinalar uma diferença corporal que merece, no mínimo, ser respeitada - deve ser considerada na tentativa de definir quem são os intersex. No entanto, não podemos esquecer a historicidade do termo, bem como o contexto social e político no qual se desenvolvem as definições biológicas sobre a intersexualidade e, conseqüentemente, a definição médica do

5 "Who is the intersex"? Retirado do site www.isna.com, em 12/06/2006; Kessler, 1995. 
termo. Esta ressalva é crucial, pois não podemos entender a "história" dos intersex, muito menos sua experiência, sem as relacionar com a experiência do corpo controlado, cuidado, construído pelos saberes médicos.

Nesse sentido, é necessário analisar como a intersexualidade se torna um estigma social. Na formulação sociológica clássica de Erving Goffman (1994), o estigma refere-se a uma situação em que o indivíduo está inabilitado para a aceitação social plena. A identificação da intersexualidade com estigma é uma das bandeiras da ISNA. Segundo Cheryl Case, ativista intersex e uma das fundadoras da ISNA, "intersexualidade é primeiramente um problema de trauma e de estigma, não de gênero". Para a autora, intersexualidade é um estigma porque borra a linha entre masculino e feminino; é de pouco conhecimento público, porque os pais são emocionalmente traumatizados pelo nascimento de uma criança com ambigüidade genital, o que lhes causa vergonha e culpa. Os pacientes são traumatizados porque eles se sentem inaceitáveis pelo modelo médico de tratamento, cuja noção de uma vida aceitável é suprimir a intersexualidade através do "spin control", por ocultamento das informações, pelas cirurgias genitais constantes e pelos tratamentos hormonais (Chase, 2002).

A ênfase dada pela ISNA em torno da questão do trauma $e$ do estigma, segundo Cheryl Chase, opõe-se à visão dos médicos e do público em geral, que interpreta a intersexualidade como um problema de identificação como gênero. A ênfase do ativismo intersex, não só da ISNA, mas dos vários movimentos, é na experiência pelas quais essas pessoas passam ao terem seus corpos des-feitos, machucados, mutilados, com perda de suas funções em prol dos discursos médicos e sociais que justificam as cirurgias como necessidade de identificar as pessoas com um gênero.

A definição da intersexualidade como um problema de estigma e de aceitabilidade cultural e não de gênero, não significa que o gênero é desconsiderado. Saber se "é menino ou menina?" é fundamental para a constituição das identidades sociais em 
nossos dias, pois o gênero é nossa identidade-chave. Como afirma Judith Butler (2003:37), é a marca do gênero que atribui existência significável para os sujeitos, qualificando-os para a vida no interior da inteligibilidade cultural. A marca do gênero qualifica os sujeitos $e$ lhes confere reconhecimento como humanos e, ainda, é a nossa identidade primeira.

No entanto, se não bastasse a condição de estigma e do tratamento médico feito precocemente, outras questões permeiam as experiências intersex, colocando-as num nível ainda mais invisibilizado, que se referem à relação entre conhecimentos científicos, práticas médicas e como estes são permeados pelos discursos de gênero. Como afirma Anne Fausto-Sterlling (2000:3), os saberes $e$ as práticas médicas não podem ser compreendidos deslocados da realidade social como um tipo de saber autônomo, neutro, técnico, científico. O conhecimento científico pode ajudar a decidir, mas são os ditames sociais $e$ as crenças no gênero que definem o sexo. Designar alguém como homem ou mulher é uma decisão social, de forma que as atitudes dos médicos são orientadas para manter os sinais $e$ as funções corporais socialmente destinadas a cada sexo.

Segundo Cabral, os protocolos médicos são atravessados por questões de gênero, sendo também misóginos, homofóbicos e heterossexistas. Na maioria dos casos criam-se corpos femininos por questões que transcendem a ordem biológica e cirúrgica, pois, tanto do ponto de vista médico e do saber biológico, quanto dos anseios sociais é mais fácil criar corpos passivos aos quais se exige pouca atividade e sensibilidade, no ditado médico, It's easier to poke a hole than to build a pole (É mais fácil cavar um buraco do que construir um poste). Criar um órgão como o pênis que possa vir a não desempenhar a funcionalidade e os atributos da masculinidade é mais complicado para a ordem cultural e social (Cabral \& Benzur, 2005:291).

Em concordância com os argumentos de Cabral, a pesquisa da socióloga Sharon Preves demonstra a mesma situação, das 37 pessoas intersex entrevistadas, em $81 \%$ dos casos as pessoas 
A teoria queer e os intersex

foram criadas como meninas e apenas $19 \%$ como meninos (Preves, 2001:30). No entanto, contrariando o mote que justifica a "feminilização", Paula Sandrine Machado (2005a) mostra que em decorrência do desenvolvimento das técnicas cirúrgicas é igualmente possível a "construção" tanto de um pênis como de uma vagina.

Os critérios levados em consideração para fazer a cirurgia também são variantes naquilo que se espera socialmente de cada gênero. Segundo Machado, para o sexo feminino, o primeiro fator considerado é a preservação da capacidade reprodutiva, depois a possibilidade em ter relações sexuais prazerosas $e$ poder ser penetrada por um pênis. Para o sexo masculino em primeiro lugar preserva-se o tamanho e a possibilidade erétil do pênis, depois a capacidade de sentir prazer, associado à ejaculação $e$ à capacidade para penetrar uma vagina $e$, finalmente, a reprodução e a possibilidade urinar em pé. Ou seja, aos homens preserva-se primeiramente a sexualidade heterossexual e para as mulheres se preserva a reprodução $e$ a maternidade.

Segundo a autora, há um cuidado maior tanto dos médicos, como das famílias, em relação à futura masculinidade do paciente operado, o que inclui um comportamento heterossexual e um pênis que funcione. Diferentemente, com as mulheres, a preocupação com a "homossexualidade" não é freqüente. Porém, a preservação da coerência identitária, ou seja, uma concordância entre sexo designado e a expressão na forma de gênero é a mesma em ambos os casos, do mesmo modo que a preservação das fronteiras entre os gêneros é fundamental (Machado, 2005b:280).

Nos casos de indivíduos intersex, a definição do corpo é fundamental não só para a atribuição do gênero, mas também para o desenvolvimento "normal", leia-se heterossexual, da sexualidade. Por isso, homens com pênis pequeno ou mulheres com clitóris grande podem ameaçar uma conduta sexual que deve se devolver em termos heterossexuais. Assim, percebe-se que a atribuição do sexo é apenas o primeiro momento do tratamento 
Nádia Perez Pino

médico da intersexualidade. Em decorrência da designação primeira, há a expectativa e o controle médico e familiar para que o gênero se desenvolva de maneira coerente com o sexo designado. Em outras palavras, a expectativa é que os indivíduos cirurgiados desenvolvam o que Butler (2003:48) chama de gêneros inteligíveis, "aqueles que mantêm e instituem relações de coerência e continuidade entre o sexo, gênero, desejo e prática sexual". A relação de continuidade, longe de ser natural, é efeito da performance de gênero, entendida como a reiteração forçada $e$ repetida das normas de gênero em atos, representações $e$ comportamentos que atribuem ao gênero um aspecto de naturalidade, assim como o mantém em sua estrutura binária $e$ heterossexual.

A experiência intersex levanta dilemas que não são fáceis de serem resolvidos. Por um lado, há indivíduos organizados reivindicando maior autonomia para gerir seus corpos e lutando para banir certas práticas e saberes científicos que marcam seus corpos e suas vidas de maneira irreversível e sem o consentimento. Por outro, há uma lógica social e cultural que bane a autonomia corporal e nega reconhecimento social àqueles que não são identificados com os ideais normativos do sexo e sua lógica binária e heterossexista. Lógica esta que perpassa todos os corpos, mas que, no caso dos intersex, se radicaliza, pois são indivíduos que nascem com corpos diferenciados, aos quais não se atribui reconhecimento como um corpo possível, mas como um corpo que tem de ser des-feito para se enquadrar naquilo que é considerado normal em nossa sociedade. Como resolver esses impasses?

Talvez esses impasses não se resolvam. Como afirma Butler, em Deshacer el Gênero (2006:22), há pessoas que vivem em situações de paradoxo identitário e este é a própria condição de suas existências. Se os ativistas intersex se mobilizam criticamente contra as normas sociais e de gênero, eles também sabem que se não incorporarem essas normas não terão vidas possíveis, ou seja, habitáveis. É por isso que as reivindicações predominantes giram 
A teoria queer e os intersex

em torno do fim da cirurgia e não um outro sexo, uma identidade intersex ou hermafrodita. Os sujeitos querem vidas habitáveis, em harmonia com o que a ordem social permite.

É por essa condição paradoxal que os intersex são um objeto paradigmático para a teoria queer. Eles mostram o cenário constritivo no qual as identidades se formam e o quão reduzido é o leque das identidades socialmente disponíveis. Além disso, a reflexão queer sobre os intersex é característica de um momento em que a teoria passou a incorporar outros sujeitos às análises $e$, ao mesmo tempo, a teoria da performatividade de gênero, um de seus pilares, passou a ser problematizada.

\section{A teoria queer e os intersex}

Os estudos queer emergem na década de 1980 como uma corrente teórica que colocou em xeque as formas correntes de compreender as identidades sociais. Descendendo teoricamente dos estudos gays e lésbicos, da teoria feminista, da sociologia do desvio norte-americana e dos pós-estruturalismo francês, a teoria queer surge em um momento de reavaliação crítica da política de identidades. ${ }^{6}$ Assim, busca evidenciar como conhecimentos $e$ práticas sexualizam corpos, desejos, identidades e instituições sociais numa organização fundada na heterossexualidade compulsória (obrigação social de se relacionar amorosa $e$ sexualmente com pessoas do sexo oposto) $e$ na heteronormatividade (enquadramento de todas as relações mesmo as supostamente inaceitáveis entre pessoas do mesmo sexo - em um binarismo de gênero que organiza suas práticas, atos e desejos a partir do modelo do casal heterossexual reprodutivo).

${ }^{6}$ Dentre seus teóricos/as destacamos Eve Kosofsky Sedgwick, Teresa de Lauretis, David Halperin, Judith Butler, Steve Seidman, Michael Warner, Beatriz Preciado, Judith Halberstan. Além das/os consideradas/os precursoras/es como Michel Foucault, Joan Scott e Gayle Rubin. 
Embora não possa ser definida como um todo único, já que em seu interior há divergências e diferenças, e querer unificá-las contraria seus objetivos políticos (Pereira, 2006), a teoria queer pode ser compreendida a partir das questões que a originaram $e$ as que, atualmente, se tornaram seu foco. O termo queer pode ser traduzido como esquisito, anormal, excêntrico e também é utilizado em tons depreciativos e homofóbicos para designar gays e lésbicas. Segundo Annemarie Jagose (1996), o termo faz parte do vocabulário semântico para entender a homossexualidade desde o século XIX e, recentemente, ganhou significado político pela incorporação teórica e adoção pelos movimentos sociais. Atualmente, é usado como um conceito guarda-chuva que abrange a coalizão da cultura sexual marginalizada, que se autoidentifica como queer, outras vezes para descrever a nascente teoria que tem se desenvolvido distante dos estudos mais tradicionais sobre gays e lésbicas. No entanto, o termo se caracteriza pela indefinição, elasticidade e abrangência, o que, para Guacira Lopes Louro (2001:546), representa "claramente a diferença que não quer ser assimilada ou tolerada, e, portanto, sua forma de ação é muito mais transgressiva e perturbadora".

A teoria queer pensa os sujeitos e as práticas sexuais que ultrapassam a oposição homossexual/heterossexual, mulher/ homem, apontando para a variedade e diversidade das subjetivações e das práticas que não se enquadram no que Judith Butler (2003:48) chama de gêneros inteligíveis, "aqueles que mantêm e instituem relações de coerência e continuidade entre o sexo, gênero, desejo e prática sexual". O queer descreve os gestos ou modelos analíticos que mostram as incoerências da suposta relação estável, revelando que a heterossexualidade não é natural, antes efeito do poder, do controle e da regulação social.

Assim, a teoria queer tem por objeto os sujeitos que não se enquadram nas matrizes de inteligibilidade de gênero. No entanto, as identidades sexuais "transgressoras" não são seu único foco, pois ela interroga os processos sociais que produzem, reconhecem, naturalizam e sustentam as identidades. Sua promessa política 
A teoria queer e os intersex

reside na crítica aos múltiplos binarismos $e$ aparentes antagonismos sociais expressos em categorias que incluem raça, gênero, classe, nacionalidade e religião, todas não apenas somadas, mas necessariamente relacionadas com a sexualidade (Eng et alii, 2005). Dispensa atenção aos indivíduos que não se conformam às regras $e$, portanto, vivem nas zonas de abjeção, lugares nos quais sua própria humanidade é contestada, exatamente por não corresponder aos ideais normativos do humano. A estratégia do queer é politizar a abjeção, impulsionar sua resignificação com a finalidade de criar estratégias de sobrevivência para que as vidas queer sejam legíveis, valorizadas, merecedoras de apoio e de reconhecimento (Butler, 2002:47).

Muitas vezes, a teoria queer é interpretada como aquela que subverte, questiona, des-constrói, pluraliza as identidades. Embora esses termos pertençam ao vocabulário comumente usado para definir suas características, isso não significa desconsiderar as identidades ou muito menos afirmar que é possível viver sem elas. O chamado para a "desconstrução" é um procedimento teórico e metodológico que tem por finalidade pensar os processos sociais e históricos que criam e naturalizam as identidades $e$ as relações de poder que as constituem. Dessa maneira, como aponta Jagose, o termo mais adequado para o procedimento teórico queer não é desconstrução, antes "desnaturalização" das identidades.

Associada a este procedimento, a teoria queer rompeu com a idéia de uma categoria unitária formadora das identidades, enfatizando a multiplicidade dos eixos de diferenciação pelos quais os indivíduos são atravessados, e como esses eixos se cruzam e se conectam, a exemplo da etnia, nacionalidade, sexualidade e classe social. O objetivo do queer era enfatizar os efeitos normalizadores, naturalizantes e excludentes das teorias que trabalhavam com categorias fechadas sobre os sujeitos $e$, ainda, definiam a priori os sujeitos que queriam representar.

No entanto, se a oposição à reivindicação das identidades foi um de seus pilares fundadores, hoje não podemos dizer que este ainda é seu o objetivo. Butler (2006) discute a suposta tensão 
Nádia Perez Pino

que pode se originar das relações entre movimentos intersex $e$ movimentos transexuais e a teoria queer, já que os movimentos estão comprometidos com a afirmação de identidades marcadas pela assimilação de sexo. Segundo a filósofa, o objetivo maior da teoria queer é opor-se à legislação não-voluntária das identidades e não apenas discutir a sua plasticidade ou seu caráter retrógrado:

ainda que a teoria queer se oponha àqueles que desejam regular a identidade e estabelecer premissas epistemológicas prioritárias para quem reclama um certo tipo de identidade, ela não só busca expandir a comunidade de ativismo anti-homofóbico, mas também insistir que a sexualidade não se resume facilmente nem se unifica através de categorização. Portanto, não se pode concluir que a teoria queer se opõe à designação do gênero ou que censura os desejos de quem espera conseguir as ditas designações para as crianças intersexuadas (Butler, 2006:22).

Nesta nova perspectiva, o importante é lutar contra as formas de legislação universal das identidades e saber discernir que o aceitável para um grupo pode não ser para os outros, distinguindo, assim, os diferentes níveis que conferem habitalidade aos indivíduos e pensando em estratégias que possam melhorar os conflitos com as normas de gênero. As críticas às normas devem situar-se no contexto em que essas vidas são vividas e guiar-se pelas condições que maximizam as possibilidades de ter uma vida habitável. Tanto os transexuais quanto os intersex reivindicam vidas habitáveis, mas essas só existem na medida em que concordam com as categorias de reconhecimento.

Nesta questão, Butler retoma a tradição hegeliana, ao afirmar que os seres humanos se tornam viáveis e têm vidas verdadeiras através de categorias de reconhecimento. No entanto, estas são moldadas de acordo com normas sociais que dizem o que é humano e o que não é. Para a filósofa, o objetivo dos movimentos em torno do gênero e sexualidade, como de seus 
A teoria queer e os intersex

pesquisadores, é questionar o que é humano, quais são os parâmetros usados para compreendê-lo, assim como o que torna as vidas habitáveis e verdadeiras. Sobretudo, alerta Butler, é essencial que a noção de humano seja mantida sempre em aberto.

A perspectiva de Butler exemplifica uma das modificações que os estudos queer sofreram ao longo da década de 1990, o que inclui o acréscimo de novos sujeitos à reflexão (como os intersex e transexuais), as críticas à teoria da performatividade - peça chave no desenvolvimento dessa corrente teórica $-e$ a necessidade de dar atenção às novas temáticas propostas por outras/os autoras/es não somente no contexto norte-americano. ${ }^{7}$ No que se refere propriamente aos intersex, esses desdobramentos localizam-se especificamente nas insuficiências da teoria da performance de gênero para os dilemas das minorias corporais, ou seja, a dificuldade em pensar os corpos, a variedade corporal $e$ as técnicas de normalização que incidem sobre os corpos, conforme apontou a teórica queer espanhola Beatriz Preciado (2004).

Preciado critica a teoria da performance de gênero, pois a considera insuficiente para pensar os processos de incorporação do sexo e do gênero. Segundo a autora, Butler teria subestimado os processos e as transformações sexuais presentes nos corpos de transexuais e transgêneros, assim como as técnicas que são destinadas para os "corpos normais", uma vez que toda a atenção é destinada à performance da paródia drag, não sem razão, as primeiras críticas à performatividade drag vieram dos movimentos transexuais.

Preciado privilegia um corte biopolítico, no qual não só a performance de gênero constrói e dá significado ao corpo, mas as "transformações corporais físicas, sexuais, sociais, políticas que ocorrem não só no cenário, mas também no espaço público" (Preciado, 2004:249). Para tanto, é necessário atentar para as

\footnotetext{
7 Sobre as mudanças na conceituação butleriana de performatividade, sua incorporação de novos sujeitos à sua teoria e sua recepção brasileira consulte Miskolci e Pelúcio, 2006.
} 
tecnologias precisas de transincorporação, assim como entender a produção biopolítica do corpo como prótese sexual. Essa postura, segundo a autora, significa uma nova etapa para os estudos queer, na qual se deixa a incapacidade de pensar a corporalidade causada pelo temor de cair numa forma de essencialismo, de pensar em alguma naturalidade do corpo.

De fato, Butler não dispensa atenção para as "chamadas minorias corporais" em Problemas de gênero ou Bodies that matter, apenas em sua obra mais recente trata da temática dos intersex, transgêneros e transexuais. No entanto, o alcance da teoria da performatividade de gênero não pode ser subestimado, tampouco supervalorizado, exatamente porque a teoria queer não se resume à teoria da performance. Conforme aponta Butler (2006:296), a teoria da performance de gênero foi o passo inicial para o desenvolvimento da teoria queer e pautou-se na perspectiva de recusar qualquer tipo de "fundacionismo biológico", de romper com o heterossexismo que imperava nos estudos feministas e por achar que aqueles que viviam fora das normas de gênero (gays, lésbicas, travestis, drags) deveriam ser merecedores de reconhecimento e de existências habitáveis (ainda que a autora não desconsidere um certo humanismo nesse segundo motivo) (Id. ib.:293).

De acordo com Butler, a situação paradoxal de confronto com as normas de gênero e, ao mesmo tempo, a necessidade de ter um mínimo de reconhecimento social para ter vidas habitáveis caracteriza os sujeitos da teoria queer. Esses sujeitos vivem em situações de paradoxo identitário como possibilidade de manter a sua existência. Pessoas que vivem em paradoxos identitários estão sujeitas ao não-reconhecimento por manterem uma relação crítica com as normas e, portanto, serem consideradas menos humanas do que as "ajustadas", as "normais". Os sujeitos queer, entretanto, são constituídos por normas e, por mais que "queiram" viver de maneira crítica e transformadora, são ameaçados por essas mesmas normas a serem invisibilizados e desfeitos como se não fosse parte do que se considera humano. Esses indivíduos sabem 
que se não incorporarem essas normas de reconhecimentos suas vidas tornam-se inabitáveis, assim, precisam buscar identidades reconhecidas. ${ }^{8}$

Continuando na perspectiva da autora, as normas de gênero fazem com que os indivíduos vivam a experiência de serem desfeitos. Algumas pessoas são desfeitas para ter reconhecimento social, outras são desfeitas exatamente por não ter este reconhecimento. O exemplo dos intersex, assim como o dos transexuais, é emblemático nessa discussão de paradoxos identitários. No caso dos intersex, à situação de paradoxo identitário se soma a de invisibilidade. As pessoas que nascem na condição de intersex necessitam categorias de reconhecimento para ter vidas habitáveis, as quais serão recebidas através da designação de um gênero. No entanto, este processo inclui intervenções corporais drásticas que podem comprometer suas vidas.

Assim, Butler sugere que os estudos queer devem se orientar para as questões que conferem "habitalidade" para os sujeitos. Essa perspectiva, guiada pela Nova Política do Gênero, reúne os movimentos transgêneros, transexual, intersex $e$ as complexas relações entre o feminismo e a teoria queer. A tarefa desses movimentos é lutar para refazer a realidade, mudar as normas que regem o humano, negociar o que é habitável ou não (Butler, 2006:52). Se os grupos ou indivíduos devem buscar o que lhes propicia vida habitável, Butler dirá que é a "violência fóbica contra os corpos que os une" (Id. ib.:24). A luta pela autonomia para gerir os próprios corpos é central nesses movimentos, principalmente em relação aos intersex. Para Butler, tanto os pesquisadores de gênero e sexualidade como os movimentos políticos devem levar em consideração a socialização da vida corporal e a situação paradoxal do mesmo. O corpo tem uma

8 A discussão que segue encontra-se em Butler (2006), especificamente na Introdução e no primeiro capítulo "Al lado de uno mesmo: em los limites de la autonomia sexual". 
Nádia Perez Pino

vulnerabilidade, que os relaciona primeiramente com os outros, com as normas sociais que regem os corpos (Id. ib.:39-40).

Para a autora, a relação entre "corpo diferente", ou menos válido, $e$ as normas tem um potencial transformador, na medida em que possibilita ir além ou refazer essa norma, ou ao menos indicar um futuro de rompimento. Os sujeitos queer, como drags, lésbicas butch/femme, transgêneros, transexuais, travestis, intersex, têm a função política de atuar no cenário político, questionando o real, as normas que incidem sobre seus corpos, e mostrando, assim, que outras formas de corpos são possíveis.

Essa inflexão no pensamento de Butler é demonstrativa da necessidade de oferecer outro tipo de interpretação para pensar o corpo sexual assim como os corpos "menos humanos". Mesmo mediante as reformulações propostas por Butler, Preciado mantém a sua posição de crítica ao que ela chama de ortodoxia da teoria da performance de gênero:

Ainda que em seus livros posteriores, inclusive no mais recente - "Desfazendo o Gênero" - Judith Butler tenha se esforçado para restituir os corpos que tinham permanecidos diluídos entre os efeitos paródicos e performáticos da lingüística, seu próprio construtivismo hegeliano the impossibilita qualquer forma de materialismo imanentista (Preciado, 2004:248).

Considerar as tecnologias que produzem, normalizam, desfazem e refazem o corpo sexual é fundamental no caso das "minorias corporais". No entanto, não é o objetivo de Preciado desconsiderar a teoria da performance, antes oferecer uma análise que se possa somar ou ainda suprir algumas das lacunas deixadas. Em relação aos intersex, percebe-se que essas tecnologias são fundamentais, uma vez que é a experiência do corpo desfeito que marca os intersex.

Assim, a reflexão queer sobre os intersex permite verificar não só como os processos de incorporação do gênero criam identidades binárias, baseadas em distinções férreas entre homens 
A teoria queer e os intersex

e mulheres, mas também como os processos sociais criam, naturalizam, o corpo num parâmetro binário. Tanto a teoria queer quanto os diversos ativismos intersex questionam essas fronteiras socialmente construídas, apontando para outras possibilidades corporais e identitárias não normativas.

\section{A experiência do corpo des-feito}

O ativista Mauro Cabral, ao relatar o que considera experiência intersex, alerta para a necessidade de não homogeneizar a subjetividade intersex, já que cada caso é único e cada sujeito reivindica o que considera melhor para a sua existência. Algumas pessoas podem se opor às cirurgias de normalização, outras, entretanto, podem reivindicar essas mesmas cirurgias para terem vidas habitáveis. No entanto, se as subjetividades são diversificadas, parte da experiência intersex se desenvolve em comum, já que se trata de pessoas que passaram por procedimentos médicos similares. Em decorrência dessa percepção, Cabral define a experiência intersexual como:

um pathos trágico, no sentido aristotélico, de um caminho de redescobrimento que não se resolve em nenhuma redenção. A subjetividade intersex se funda na intensidade de uma experiência de estranhamento. Nesse sentido a experiência intersex é um produto paradoxico, cruelmente paradoxico, dos procedimentos médicos destinados a erradicá-la (Cabral \& Benzur, 2005:295).

Assim, a experiência intersex revela a história de corpos controlados por saberes e práticas médicas, submetidos a uma variedade de tipos de normalização que visam não só designar o "sexo verdadeiro", mas também a correlação entre corpo, comportamento, sexualidade e caracteres secundários do corpo (barba, seios, pêlos, entonação da voz, largura dos ombros). Essa experiência suscita importantes reflexões acerca de como os corpos são construídos em nossas sociedades e sua importância 
Nádia Perez Pino

biopolítica para a construção das identidades, assim como o estranhamento causado por corpos que não se enquadram nos ideais normativos e que "precisam" ser des-feitos para atingir um mínimo de humanidade.

Esse controle médico, contudo, é historicamente localizável nas sociedades modernas, mais especificamente em meados do século XIX, quando se iniciou o desenvolvimento das teorias $e$ controle sobre a variedade do corpo sexual, assim como das sexualidades "perversas". Mesmo correndo o risco de simplificar, pode-se dizer que desde que a intersexualidade ou hermafroditismo passou a ser considerada uma patologia $e$ um assunto de interesse exclusivo das ciências biomédicas, as perguntas "Onde se localiza o verdadeiro sexo?" e "quais os critérios para designar o sexo?" tornaram-se a tônica dominante. Desde então os saberes biomédicos buscam as "causas" $e$, principalmente, as características que devem ser levadas em consideração na hora de definir o sexo.

O trecho abaixo, retirado do periódico Arquivos Brasileiros de Endocrinologia e Metabologia (2005), em um volume dedicado inteiramente a discutir a intersexualidade, é ilustrativo das dúvidas da medicina em relação à temática:

Infelizmente, ainda não há respostas para muitas questões cruciais quanto à etiologia, fisiopatologia e prognóstico individual e familiar em diversas situações. Se, por um lado, a existência de tantas questões em aberto instiga e fascina os pesquisadores dessa área, por outro lado é fonte de angústia no momento da definição do sexo de criação de recém-nascidos com ambigüidade genital. "Como fazer a escolha menos ruim?" - esse é o desafio a ser vencido nos dias de hoje (Maciel-Guerra \& Guerra Jr., 2005:2).

Atualmente, a decisão sobre o sexo do recém-nascido é tomada em conjunto por diversos profissionais endocrinologistas, pediatras, urologistas, psicólogos, cirurgiões, geneticistas - com o apoio da família. Essa postura é característica 
A teoria queer e os intersex

das mudanças pelas quais os saberes médicos passaram ao longo do tempo, motivadas não só pelo pelos avanços no conhecimento científico, mas, principalmente, pela ação dos ativismos intersex $e$ por divergências no interior da própria medicina em relação aos procedimentos médicos instaurados na década de 1950.

A história da intersexualidade é comumente descrita em três grandes períodos. ${ }^{9}$ A "era das gônadas" - assim nomeada, porque os critérios usados para definir alguém como hermafrodita baseavam-se na presença simultânea tanto das gônadas masculina quanto feminina - data de meados do século XIX e vai até os anos de 1950 e caracteriza-se pelo início das classificações médicas sobre os variados tipos de "hermafroditismo". Neste período, surgem as primeiras classificações usadas ainda nos dias de hoje, como as de verdadeiro e de falso hermafrodita.

O segundo período - "Era cirúrgica" -, iniciado na década de 1950 e tem seu fim por volta dos anos de 1980. Esse período é crucial para entender a história dos intersex, pois nessa época são realizadas as primeiras cirurgias para "construir" o sexo. Os avanços nas técnicas, assim como da anestesia, contribuíram para o início das cirurgias, mas foi crucial a emergência do paradigma de identidade de gênero, do psicólogo e sexologista John Money. Baseado na teoria dos papéis sociais de Talcott Parsons, Money afirmava que as pessoas nascem com identidades neutras $e$ gênero e o sexo poderiam ser mudados em até 18 meses, uma vez que as gônadas, hormônios e cromossomos não determinam automaticamente o gênero. O comportamento sexual não viria totalmente de um "instinto natural" e sim da educação e dos processos de socialização. Apesar da ênfase nos aspectos sociais, a natureza e a binariedade do sexo não foram colocadas em xeque, pois os intersex eram considerados frutos de desenvolvimento anormal e necessitavam de tratamentos para se tornar homens $e$ mulheres (Fausto-Sterling, 2000:46).

9 Uma reconstrução histórica sobre os saberes científicos e médicos sobre a intersexualidade pode ser encontrada em Fausto-Sterling, 2000 e Dreger, 1998. 
Nádia Perez Pino

Assim, "rompia-se" com a idéia de que havia um "verdadeiro sexo", possibilitando que as crianças intersex pudessem ter corpos considerados "normais", em contrapartida inaugurava-se uma era de intervenções drásticas nos corpos intersexuados. O cirurgião pediatra, baseado nas possibilidades cirúrgicas apresentadas pela anatomia, designava o sexo da criança que seria chamado de "sexo de criação". De acordo com as prescrições de Money, recomendava-se que as crianças intersexuadas não deveriam saber os motivos da operação $e$ muito menos de sua condição; do ponto de vista médico tal revelação poderia interferir na sua identidade de gênero (SpinolaCastro, 2005:52).

$\mathrm{O}$ que parecia ser a solução tornou-se um pesadelo para as pessoas que sofreram as primeiras cirurgias quando crianças $e$, no final da década de 1980, passaram a contestá-las. Esses procedimentos que, destinados a criar corpos normais, na verdade, criavam corpos traumatizados, mutilados, sem sensibilidade e com perdas de funções. A associação em grupos de auto-ajuda e a publicação de biografias foram as maneiras mais eficazes para tornar públicas, ou menos invisíveis, as histórias de vida dessas pessoas. A medicina reviu várias de suas práticas e inaugurou-se a "Era do consenso", na qual o sexo a ser designado é decidido em colaboração com uma equipe multidisciplinar e com a ajuda dos pais.

Hoje, os diferentes ativismos intersex espalhados por vários países têm por objetivo primeiro banir essas cirurgias que desfazem e re-fazem esses corpos em prol de discursos sobre a não aceitabilidade social desses corpos "estranhos". A medicina não é a grande vilã da história, antes, é parte da ordem social que exige que as pessoas tenham um sexo verdadeiro - homemmasculino $e$ mulher-feminina - e que essa verdade esteja sinalizada no corpo. A anatomia ainda funciona como o lugar primário para anunciar a verdade dos sujeitos.

No entanto, a associação direta de que dois corpos incomensuravelmente diferentes formam dois gêneros é criação 
recente; a história da diferença sexual não pode mais ser negligenciada pelas teorias e práticas, que as tomam como fundamento inquestionável das diferenças e relegam as ambigüidades para as salas cirúrgicas, como conseqüência, tanto os ativismos intersex quanto a teoria queer contemporânea afirmam a possibilidade não normalizadora de corporalidades, ou seja, a visibilização da experiência de sujeitos queer que, em corpos paradoxais para a ordem de gênero vigente, também têm o direito de ser reconhecidos como humanos, não-abjetos, merecedores de vidas habitáveis.

\section{Referências bibliográficas}

BORDO, Susan R. O corpo e reprodução da feminilidade: uma apropriação feminista de Foucault. In: JAGGAR, Alison M. \& BORDO, Susan R. Gênero, Corpo e Conhecimento. Rio de Janeiro, Record, Rosa dos Ventos, 1997, pp.19-41.

BuTLER, Judith. Deshacer el Género. Barcelona, Paidós, 2006.

Problemas de Gênero. Feminismo e subversão da identidade, Rio de Janeiro, Civilização Brasileira, 2003.

Cuerpos que importan - sobre los limites materiales y discursivos Del "sexo". Buenos Aires, Anagrama, 2002.

CABRAL, Mauro. Pensar la intersexualidad, hoy. In: Maffia, Diana. (org.) Sexualidade migrantes - Género e Transgéneros. Buenos Aries, Feminaria Editora, 2003.

\& BENZUR, Gabriel. Cuando digo intersex. Um dialogo introductorio a la intersexualidad. cadernos pagu (24), Núcleo de Estudos de Gênero - Pagu/Unicamp, 2005.

CHASE, Cheryl. What is the agenda of the intersex patient advocacy movement? Prepared for First World Congress: Hormonal and Genetic Basis of Sexual Differentiation Disorders, Tempe Arizona, May 17-18 2002. Retirado do site www.isna.com em 12/05/2006

CORRÊA, Mariza. Fantasias Corpóreas. In: PISCITELLI, Adriana; GREGORI, Maria Filomena; CARRARA, Sérgio. (orgs.) Sexualidade e Saberes: Convenções e Fronteiras. Rio de Janeiro, Garamond, 2004. 
Nádia Perez Pino

DREGER, Alice. Hermaphrodites and the medical invention of sex. Cambridge, Harvard University Press, 1998.

ENG, David L.; HALBERTSM, Judith; MUÑOS, Esteban. Introduction "What's queer about studies now?" Social Text 84-85, vol.23, 2005, pp.1-17.

Fausto-STerling, Anne. Sexing the Body: Gender Politics and the Construction of Sexuality. New York, Basic Books, 2000.

GofFMAN, Erving. Estigma - Notas sobre a Manipulação da Identidade deteriorada. Rio de Janeiro. Zahar Editores, 1994.

JAGOSE, Annemarie. Queer Theory - An Introduction. New York, New York University Press, 1996.

KESSLER, Suzane J. Meanings of gender variability constructs of sex and gender. 1995. Retirado do site www.isna.com, em 25/06/2005.

LOURO, Guacira Lopes. Teoria queer - uma política pós-identitária para a educação". Revista Estudos Feministas, vol. 9, nº 2. Florianópolis 2001.

MACHADO, Paula Sandrine. "Quimeras" da ciência: estudo antropológico sobre as representações de profissionais da saúde acionadas em casos de genitália ambígua. Revista Brasileira de Ciências Sociais, vol. 20, n 50, São Paulo, 2005a.

O sexo dos anjos: um olhar sobre a anatomia e a produção do sexo (como se fosse) natural. cadernos pagu (24), Núcleo de Estudos de Gênero - Pagu/Unicamp, 2005b.

MACIEL-GuerRA, Andréa T. \& GuerRA JR., Gil. Intersexo: entre o gene e o gênero. Arquivo Brasileiro de Endocrinologia e Metabolismo, vol. 49, n 1, São Paulo, jan./feb. 2005.

MISKOLCI, Richard e PELÚCIO, Larissa. Fora do Sujeito e Fora do Lugar: reflexões sobre performatividade a partir de uma etnografia entre travestis. CD Anais do XXX Encontro Anual da ANPOCS - GT Sexualidade, Corpo e Gênero -, 2006.

PereIRA, Pedro Paulo Gomes. A teoria queer e a reinvenção do corpo resenha. Cadernos Pagu (27), Núcleo de Estudos de Gênero Pagu/Unicamp, julho-dezembro de 2006, pp.469-477. 
A teoria queer e os intersex

PRECIADO, Beatriz. Entrevista a Jesús Carrilo, 18 de outubro de 2004, retirado do site: http://www.arteleku.net/4.0/pdfs/preciado.pdf [publicado neste volume]

PREVES, Sharon Elaine. Negotiating the constraints of gender binarism: intersexuals challenge to gender categorization. Current Sociology, 48 (3), 2001.

ScotT, Joan W. A Invisibilidade da Experiência. Projeto História 16, São Paulo, fevereiro de 1998, pp.297-325.

SPINOLA-CASTRO, Ângela Maria. A Importância dos Aspectos Éticos e Psicológicos na Abordagem do Intersexo. Arquivo Brasileiro Endocrinologia Metabologia, vol. 49, nº 1, Fevereiro de 2005. 